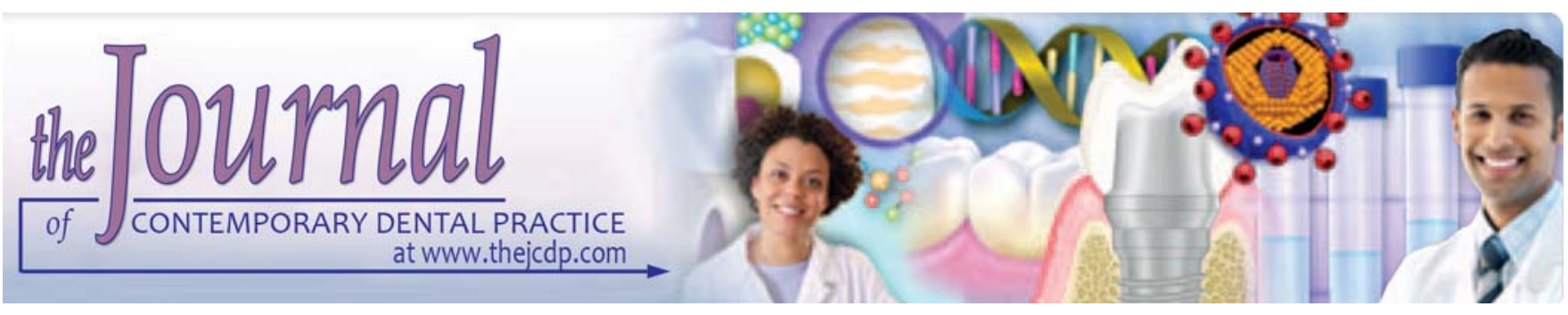

\title{
Supernumerary Lateral Incisor
}

\author{
Annapurna Kini, M Manjunatha, N Shubhashini, Shija, VC Sunil Kumar, DN Jayashankar
}

\begin{abstract}
Supernumerary teeth are common in general population and occur frequently in patients with familial trait. However, it is rare to find supernumeraries in individuals with no associated disease or syndrome. Supernumerary teeth are found in any region of maxilla and mandible, with a predisposition for anterior maxilla. A case of endodontically involved supernumerary lateral incisor is described.
\end{abstract}

Keywords: Supernumerary teeth, Supplemental teeth, Mendelian principles.

How to cite this article: Kini A, Manjunatha M, Shubhashini N, Shija, Kumar VCS, J ayashankar DN. Supernumerary Lateral Incisor. J Contemp Dent Pract 2013;14(1):129-132.

\section{Source of support $\mathrm{Nil}$}

Conflict of interest: None declared

\section{INTRODUCTION}

Supernumerary teeth may be defined as any teeth or tooth substance in excess of the usual configuration of 20 deciduous, and 32 permanent teeth. This surplus can also be accompanied by a deficit of other teeth. Supernumerary teeth may occur in singles, multiples, unilaterally or bilaterally, in one or both the jaws. ${ }^{1,2}$

The prevalence of supernumerary teeth ranges between 0.3 to $0.8 \%$ in the primary dentition and 0.1 to $3.8 \%$ in the permanent dentition. The most common site affected with one or two supernumerary teeth is the anterior maxilla, followed by mandibular premolar region. $M$ andibular premolar area is the most common site affected by multiple supernumerary teeth. Supernumerary teeth occur 8.2 to 10 times more frequently in the maxilla than the mandible, and the most commonly affected site being the premaxilla. ${ }^{3-5}$

Sexual dimorphism is reported with males being more commonly affected. The male: female ratio being $2: 1 .{ }^{6} \mathrm{~T}$ he etiology of supernumerary teeth may be partly genetic; however, the inheritance pattern may not follow the Mendelian principles. Environmental patterns can play a minor role in the etiology of supernumerary teeth. ${ }^{2}$ Presence of supernumerary teeth can be associated with complications, such as crowding, delayed eruption, diastema, cystic lesions, rotations and resorption of adjacent teeth. ${ }^{6}$

This article reports a case of single unilateral supernumerary tooth adjacent to maxillary left lateral incisor with associated periapical pathology.

\section{CASE REPORT}

A 21-year-old male patient presented with the chief complaint of pain and pus discharge from his upper left anterior tooth region. On intraoral examination a supplemental tooth was found adjacent to maxillary left lateral incisor. Sinus opening was observed associated with the supplemental tooth (Fig. 1). On radiographic examination, periapical radiolucency was observed associated with the roots of the lateral incisor and the supplemental tooth (Fig. 2). The sinus tract was traced using a no. 25 gutta percha and radi ograph was taken. The guttapercha was seen pointing toward the root of the tooth mesial to the left maxillary canine. Pulp vitality test was done using electric pulp tester to confirm the pulpal status. The supplemental tooth adjacent to the maxillary left central

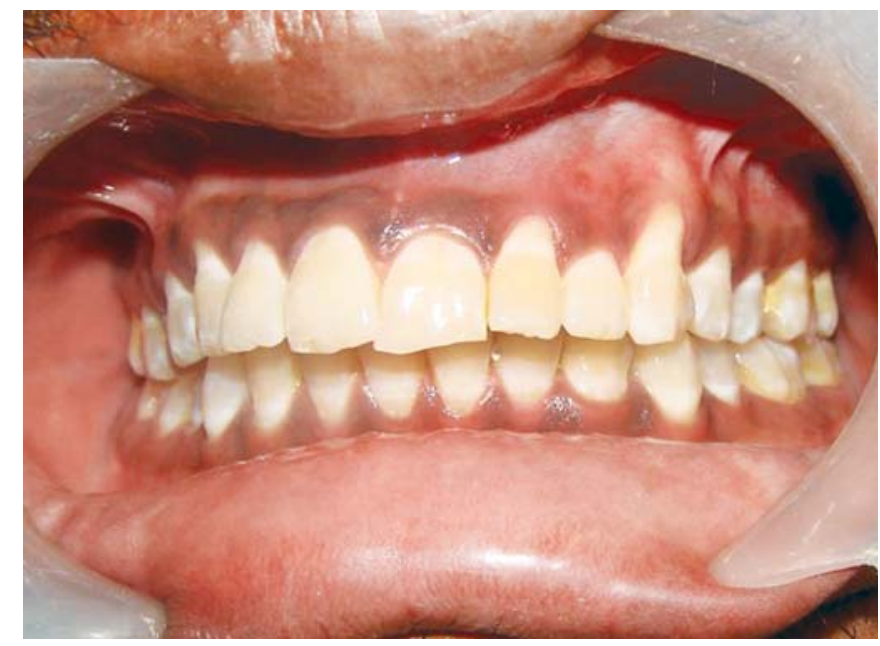

Fig. 1: Supplemental lateral incisor 


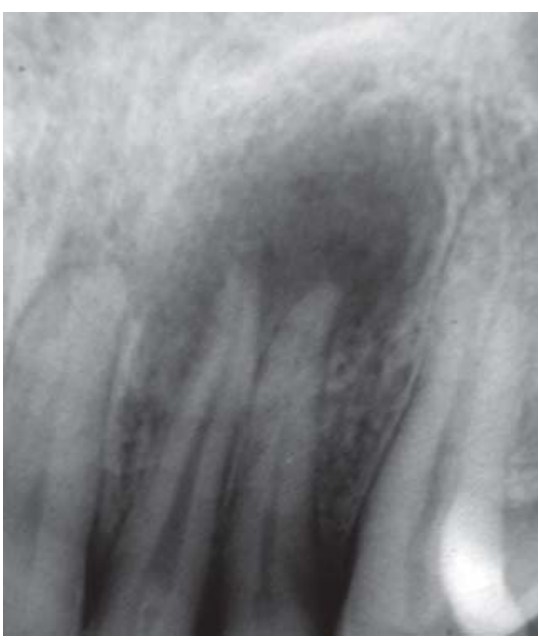

Fig. 2: Preoperative radiograph

incisor was recorded as no response to the vitality test and the tooth mesial to left maxillary canine had positive response to vitality. The tooth did not disturb the esthetics or function of the patient. Developmental disorders associated with supernumerary teeth were excluded in the case. Treatment plan included root canal therapy for supplemental tooth.

Local anesthesia was administered (X ylocaine 2\% adrenaline). Isolation was done using rubber dam (Hygenic, Coltene/W haledent Inc) (Fig. 3). A ccess opening of supplemental tooth was carried out using an endo-access bur. W orking length of $21 \mathrm{~mm}$ was established using $\mathrm{K}$ file no. 15 (G rossman's method) (Fig. 4). Step-back method of preparation was followed for preparing the canal using $\mathrm{K}$ files. M aster apical file was $\mathrm{K}$-file no. 40 . The irrigants used were $2.5 \%$ sodium hypochlorite and normal saline. The canal was then dried using absorbant paper points and filled with calcium hydroxide paste (M etapex, B ioM ed) (Fig. 5). Closed dressing was then placed.

In the subsequent appointment the sinus opening had healed. The patient was asymptomatic. The canal was then

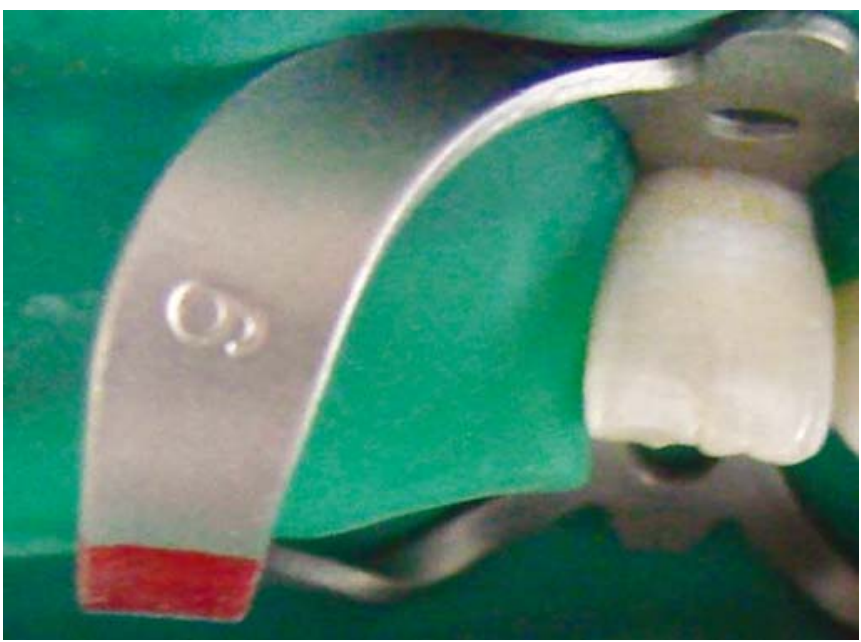

Fig. 3: Rubber dam isolation

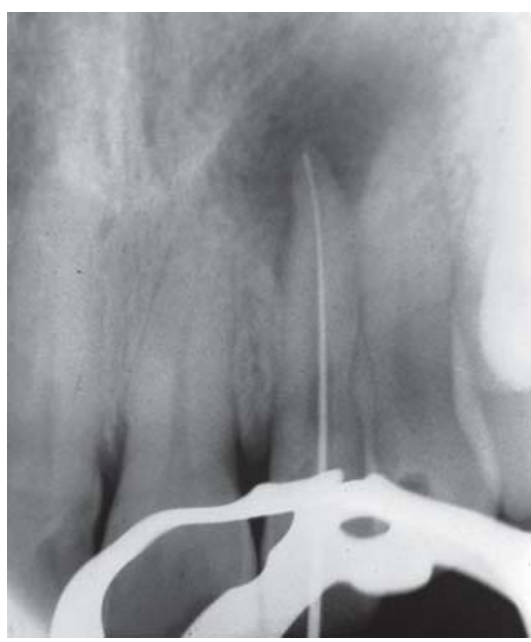

Fig. 4: Working length determination

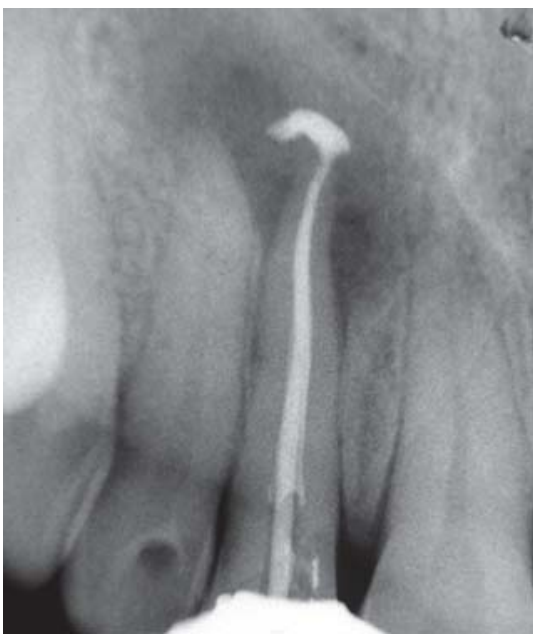

Fig. 5: Intracanal medication

debrided of calcium hydroxide. Mastercone selection was done. Canal was dried and obturated using lateral condensation technique (Fig. 6). A ccess cavity was then sealed using glass ionomer cement. Early treatment goals were achieved without complication and the patient is under regular review (Fig. 7).

\section{DISCUSSION}

This case describes a case of supplemental, unilateral lateral incisor. The tooth was involved with periapical lesion rendering it nonvital. Presence of supernumerary teeth can greatly compromise on the esthetics. A lthough, there is a great wealth of information on normal tooth development, the genetic etiology and molecular mechanisms that lead to congenital deviations in tooth number is not completely understood. V arious theories are proposed to support the pattern of presentation and incidence of supernumerary teeth:

1. Dental lamina that fail to degenerate, become reactivated to form accessory tooth organs. 


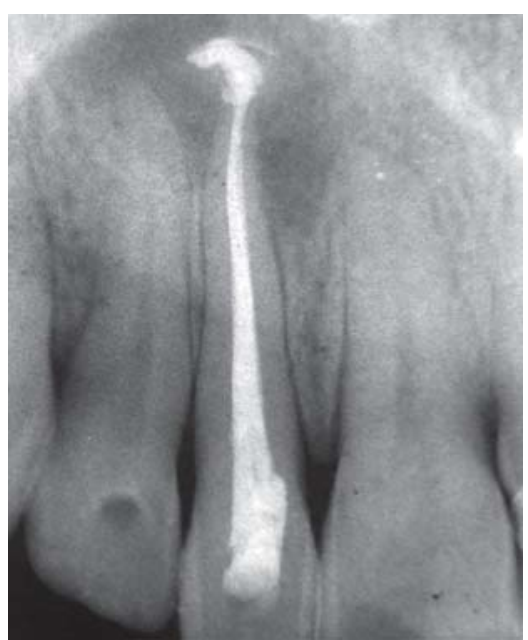

Fig. 6: Immediate obturation radiograph

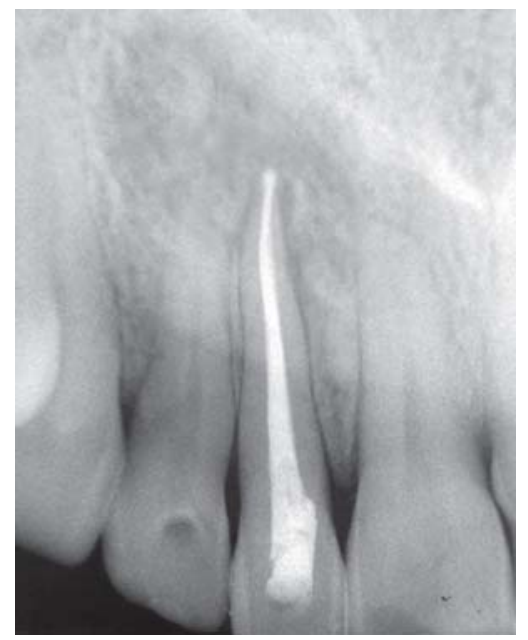

Fig. 7: Follow-up radiograph after 1 year

2. The dental lamina continues to proliferate due to fail ure, if programmed cell death, which may be brought on by defects in signaling between epithelium and mesenchyme.

3. Supernumerary teeth may arise from division of single tooth bud. ${ }^{7,8}$

4. May be partly genetic, since the supernumerary teeth are commonly found in the relatives of affected individuals; however, inheritance pattern does not follow M endelian principles. ${ }^{2}$

In addition to the theories suggested about the etiology, phylogenetic process of atavism, syndromes and medical conditions are also proposed as the etiological factors.

The medical conditions and the syndromes associated with supernumerary teeth are:

1. A utosomal dominant conditions like syndromic cleft lip and palate, cleidocranial dysplasia, Gardner syndrome and N ance-Horan syndrome.

2. X-linked conditions like focal dermal hypoplasia syndrome and orofaciodigital syndromes types I and II

3. A utosomal recessive disorders like steroid dehydrogenase deficiency and Rothmund- Thomson syndrome. ${ }^{9,10}$
Supernumerary teeth are classified according to morphology and location.

I. Four different morphological types of supernumerary teeth have been described:

1. Conical-these are the most commonly found supernumerary teeth. These teeth have conical or triangular shaped crowns with complete root formation. These teeth are commonly located between maxillary central incisors. Relative occurrence is $75 \%{ }^{7,11}$

2. Tuberculate- these teeth are usually barrel-shaped with the crown having multiple tubercles. These teeth usually present with incomplete or no root formation. These are most commonly seen palatal to maxillary incisors. Relative rate of occurrence is $12 \%$.

3. Supplemental-these usually resemble their respective normal teeth. M ost common supplemental tooth is the maxillary lateral incisor, followed by lesser frequency affecting the premolars and the molars. Relative rate of occurrence is $7 \%$.

4. Odontomes- these are considered to be benign, disordered overgrowths of mature tissue (hamartomas) comprising dental tissues appearing as radiopaque lesions in tooth-bearing areas. These can be of two types: Compound and complex odontomes. Compound odontome comprises of small, separate tooth-like structures, whereas complex odontome is a single irregular mass of tissue that does not resemble the tooth structure. Relative rate of occurrence is $6 \% .{ }^{11}$

II. Based on the location, supernumerary teeth are classified as:

1. Mesiodens: Conical supernumerary tooth located between and palatal to maxillary central incisors.

2. Paramolar: Supernumerary molar situated buccally or lingually/palatally to the molar or in the interproximal space buccal to second and third molar.

3. Distomolar: A rudimentary supernumerary tooth located distal to third molar.

4. Parapremolar: Supernumerary tooth resembling a premolar that forms in the premolar region. ${ }^{12}$

Supernumerary teeth may erupt normally or may remain impacted, inverted or may have an abnormal path of eruption. These may be diagnosed arbitrarily on the radiograph with no associated complications. The complications that may be associated with supernumerary teeth are as follows:

- Prevention or delay of eruption of associated permanent teeth

- Displacement or rotation of permanent teeth

- Crowding 
- Incomplete space closure during orthodontic treatment

- Dilacerations, abnormal or delayed root development of associated permanent teeth

- Root resorption of adjacent teeth

- Complications associated with supernumerary teeth itself, which includes cyst formation, migration into the nasal cavity, maxillary sinus or hard palate

- Late-forming supernumerary teeth. ${ }^{11}$

\section{CONCLUSION}

Supernumerary teeth are of common occurrence commonly associated with complications. The clinician should recognize the presence of supernumerary teeth and should manage the condition appropriately to minimize the complications.

\section{REFERENCES}

1. Schulze C. Developmental abnormalities of the teeth and jaws. In: Gorlin RJ, Goldman HM (Eds). Thoma's oral pathology. St Louis: CV M osby 1970:112-22.

2. Scheiner M A, Sampson WJ . Supernumerary teeth: A review of the literature and four case reports. A ust Dent J 1997;42:16065.

3. Schulze C. Incidence of supernumerary teeth. Dent A bstr 1961;6:23.

4. Y usof WZ. Non-syndrome multiple supernumerary teeth: Literature review. J Can D ent A ssoc 1990;56:147-49.

5. Nazif M N, R uffalo RC, Zullo T. Impacted supernumerary teeth: A survey of 50 cases. J A m Dent A ssoc 1983;106:201-04.

6. Patchett CL, Crawford PJ M, Cameron A C, Stephens CD. The management of supernumerary teeth in childhood: $A$ retrosperctive study of practice in Bristol Dental Hospital, England and W estmead Dental Hospital, Sydney, A ustralia. Int J Pediatr Dent 2001;11:259-65.

7. Rajab LD, Hanmdan MAM. Supernumerary teeth: Review of the literature and a survey of 152 cases. Int J Paediatr Dent 2002;12:244-54.

8. Sasaki H, Funao J, M orinaga $\mathrm{H}, \mathrm{N}$ akano K, O oshima T. M ultiple supernumerary teeth in the maxillary canine and mandibular premolar regions: A case in the postpermanent dentition. Int J Paediatr D ent 2007;17:304-08.
9. Zhu JF, M arcushamer M, King DL, Henry RJ. Supernumerary and congenitally absent teeth: A literature review. J Clin Pediatr Dent 1996;20:87-95.

10. D'Souza R N, K lein OD. U nraveling the molecular mechanisms that lead to supernumerary teeth in mice and men: Current concepts and novel approaches. Cells Tissues Organs 2007; 186:60-69.

11. Shah A, Gill DS, Tredwin C, Naini FB. Diagnosis and management of supernumerary teeth dental update 2008;35: 510-20.

12. V on AT. Anterior maxillary supernumerary teeth: A clinical and radiographic study. A ust Dent J 1992;37:189-95.

\section{ABOUT THE AUTHORS}

\section{Annapurna Kini (Corresponding Author)}

Reader, Department of Conservative Dentistry and Endodontics Rajarajeshwari Dental College and Hospital, B engaluru, Karnataka India, e-mail: kinimai@gmail.com

\section{Manjunatha}

Reader, Department of Conservative Dentistry and Endodontics B habha College of D ental Sciences, B hopal, M adhya Pradesh, India

\section{N Shubhashini}

Reader, Department of Conservative Dentistry and Endodontics Rajarajeshwari D ental College and Hospital, B engaluru, K arnataka India

\section{Shija}

Senior Lecturer, Department of Conservative Dentistry and Endodontics, Rajarajeshwari Dental College and Hospital, B engaluru K arnataka, India

\section{VC Sunil Kumar}

Professor, Department of Conservative Dentistry and Endodontics Bhabha College of D ental Sciences, B hopal, M adhya Pradesh, India

\section{DN Jayashankar}

Reader, Department of Conservative Dentistry and Endodontics RK DF College of D ental Sciences, B hopal, M adhya Pradesh, India 